\title{
A randomised trial comparing the pharmacokinetics and safety of the biosimilar CT-P6 with reference trastuzumab
}

\author{
Francisco J. Esteva ${ }^{1} \cdot$ Justin Stebbing ${ }^{2} \cdot$ Rebecca N. Wood-Horrall $^{3} \cdot$ Peter J. Winkle ${ }^{4} \cdot$ Sung Young Lee . $^{5}$ \\ Sang Joon Lee ${ }^{5}$
}

Received: 11 August 2017 / Accepted: 28 December 2017 / Published online: 12 January 2018

(C) The Author(s) 2018. This article is an open access publication

\begin{abstract}
Purpose Access to trastuzumab, a valuable anti-cancer treatment, can be limited by cost. The primary aim of this study was to evaluate and compare the PK profiles of CT-P6, a biosimilar of trastuzumab, and US-licensed reference trastuzumab $\left(\right.$ Herceptin ${ }^{\circledR}$ ) in healthy subjects. Secondary study aims included comparison of the safety and immunogenicity of CT-P6 and reference trastuzumab in these subjects.

Methods We performed a single-dose, randomised, double-blind, parallel group study (NCT02665637) comparing CT-P6 with reference trastuzumab $(6 \mathrm{mg} / \mathrm{kg}, 90 \mathrm{~min}$ intravenous infusion) in 70 healthy adult males. Pharmacokinetics, safety and immunogenicity were evaluated up to 10 weeks post-dose. Primary endpoints were area under the serum concentration-time curve (AUC) from time 0 to infinity $\left(\mathrm{AUC}_{\mathrm{inf}}\right)$; $\mathrm{AUC}$ from time 0 to last quantifiable concentration $\left(\mathrm{AUC}_{\text {last }}\right)$; and observed maximum serum concentration $\left(C_{\max }\right)$. The pre-determined equivalence criterion was a $90 \%$ confidence interval of $80-125 \%$ for ratios of geometric least squares (LS) means.

Results Equivalence of CT-P6 and reference trastuzumab was demonstrated. Ratios (CT-P6/reference trastuzumab) of geometric LS means $\left(90 \%\right.$ confidence interval) were: $\mathrm{AUC}_{\text {inf }} 99.05(93.00,105.51)$; $\mathrm{AUC}_{\text {last }} 99.30(92.85,106.20) ; C_{\max } 96.58$ $(90.93,102.59)$. Safety profiles were similar; treatment-emergent adverse events occurred in ten subjects $(28.6 \%)$ in the CT-P6 group and 11 (31.4\%) in the reference trastuzumab group. No serious adverse events or deaths occurred. No subjects tested positive for anti-drug antibodies.

Conclusions These data add to the totality of evidence required to demonstrate biosimilarity. A phase III study of CT-P6-in which equivalent neoadjuvant efficacy to reference trastuzumab has been demonstrated—is ongoing.
\end{abstract}

Keywords Biosimilar $\cdot$ CT-P6 $\cdot$ Equivalence $\cdot$ Pharmacokinetics $\cdot$ Safety $\cdot$ Trastuzumab

Electronic supplementary material The online version of this article (https://doi.org/10.1007/s00280-017-3510-7) contains supplementary material, which is available to authorized users.

Sang Joon Lee

SangJoon.Lee@celltrion.com

1 NYU Langone Health, New York, NY 10016, USA

2 Imperial College and Imperial College Healthcare NHS Trust, London, UK

3 PPD Phase I Clinic, Austin, TX 78744, USA

4 Anaheim Clinical Trials, Anaheim, CA 92801, USA

5 CELLTRION Inc, 23 Academy-ro, Yeonsu-gu, Incheon 22014, Republic of Korea

\section{Introduction}

Trastuzumab, a recombinant humanised monoclonal antibody $(\mathrm{mAb})$, targets the human epidermal growth factor receptor 2 (HER2), a receptor tyrosine kinase [1]. Although HER2 has no known ligand it is able to dimerise, a process that can be induced by HER2 over-expression [2]. Dimerisation and subsequent HER2-mediated signalling increase cell proliferation and inhibit apoptosis [2]. HER2 over-expression occurs in up to $30 \%$ of all breast cancers [3] and at a similar rate in gastric cancers [4]. Over-expression is associated with decreased time to recurrence and poorer prognosis in breast cancer [3,5], and may be linked to worse prognosis and increased recurrence in gastric cancer $[4,6]$.

Trastuzumab binding to HER2 leads to antibody-dependent cell-mediated cytotoxicity (ADCC) and inhibition of 
cell proliferation [1]. Originator or 'reference' trastuzumab (Herceptin ${ }^{\circledR}$ ) is approved for the adjuvant treatment of HER2-positive (HER2 + ) breast cancer, the treatment of HER2 + metastatic breast cancer (MBC) and HER2 + metastatic gastric or gastroesophageal junction adenocarcinoma in the USA [7], and of HER2 + MBC, HER 2 + early breast cancer (EBC) and HER2 + metastatic gastric or gastroesophageal junction adenocarcinoma in Europe [8]. The combination of reference trastuzumab with chemotherapy in HER 2 + breast cancer has been shown to improve response rates, reduce recurrence risk and increase survival, compared with chemotherapy alone [9-13], findings that support the inclusion of this approach in European $[9,14]$ and USA [15-17] treatment guidelines. Such combination therapy also increases survival, compared with chemotherapy alone, in advanced HER 2 + gastric or gastroesophageal junction cancers [18], as reflected in clinical guidelines [19-21].

The use of biological therapies has advanced cancer treatment but also significantly increased treatment costs, with, for example, one course of reference trastuzumab costing approximately US $\$ 70,000$ [22]. When considered alongside increasing cancer prevalence, particularly in developing nations, and a growing and ageing global population, this financial burden to healthcare systems may soon reach unsustainable levels [23, 24]. As reference product patents expire, biosimilar products can be developed and introduced, providing a potential means to reduce this financial burden [25] and enhance patient access to treatment [26]. A biosimilar is a biological medicinal product similar to one already authorised (the 'reference product') and expected to have similar clinical efficacy and safety profiles, as determined by comprehensive comparability assessments [27]. CT-P6 (CELLTRION, Incheon, Republic of Korea) is a biosimilar of reference trastuzumab, already approved in South Korea for the same indications as the reference product [28]. CT-P6 has been found to be similar to reference trastuzumab in in vitro studies, including with respect to HER2 binding affinity, ADCC and anti-proliferation activity. CT-P6 also exhibited a similar profile to reference trastuzumab in in vivo toxicology studies [CELLTRION Inc., data on file].

Due to the complexity of manufacturing biological products, it is impossible to create a biosimilar that is identical to a reference product, just as no two batches of reference product can be identical. It is, therefore, necessary to demonstrate that no clinically meaningful differences are expected between the two, before a biosimilar can be approved by regulatory authorities $[27,29,30]$. This includes demonstration of analytical and non-clinical similarity as well as comparable clinical pharmacokinetics (PK), efficacy, safety and immunogenicity [27, 30]. The US Food and Drug Administration (FDA) requires that at least one clinical PK study demonstrating similarity to an FDA-licensed product is conducted [29], while the European Medicines Agency (EMA) also considers a comparative clinical PK study to be essential [27]. The primary aim of the current study was to evaluate and compare the PK profiles of CT-P6 and US-licensed reference trastuzumab in healthy subjects. Secondary study aims were to assess additional PK parameters and the safety and immunogenicity of CT-P6 and reference trastuzumab in these subjects.

\section{Materials and methods}

\section{Study design and ethics}

This phase I single-dose study was approved by an investigational review board (IntegReview IRB; Austin, TX, USA) and performed in accordance with the ethical standards as laid down in the 1964 Declaration of Helsinki and its later amendments or comparable ethical standards, and International Conference on Harmonization Good Clinical Practice guidelines. Informed consent was obtained from all individual participants included in the study. The study was a 10-week, double-blind, two-arm, parallel-group trial comparing CT-P6 with reference trastuzumab (Fig. 1). The study was conducted at two centres in the USA (PPD Phase I Clinic, Austin, TX and Anaheim Clinical Trials, Anaheim, CA). The trial was registered with ClinicalTrials.gov (Study Number NCT02665637).

\section{Subject eligibility criteria}

Eligible subjects were healthy males aged between 18 and 55 years inclusive, with a body mass index of $18.0-29.9 \mathrm{~kg} /$ $\mathrm{m}^{2}$ and a body weight of $55.0-99.9 \mathrm{~kg}$. The trial included a sub-population of subjects of Japanese ethnicity within each treatment arm, in line with Japanese Pharmaceuticals and Medical Devices Agency requirements. Exclusion criteria encompassed a number of medical conditions, including a history or presence of hypersensitivity; allergy; clinically significant atopic allergy; infection requiring systemic antiinfective treatment within 14 days of study randomisation; a history of congestive heart failure; and an abnormal left ventricular ejection fraction (LVEF) within 3 weeks of study randomisation. Subjects were excluded from the study if they had any previous exposure to mAbs or current use of biologics. Subjects were also excluded if they had used prescription or non-prescription medications or dietary supplements within 7 days or five half-lives prior to dosing (any herbal supplements were discontinued 28 days before dosing), or treatment with an investigational drug or participation in a clinical trial within 30 days or five half-lives prior to dosing. Moderate or heavy tobacco smokers were not eligible for the study, nor were subjects exhibiting evidence of drug 


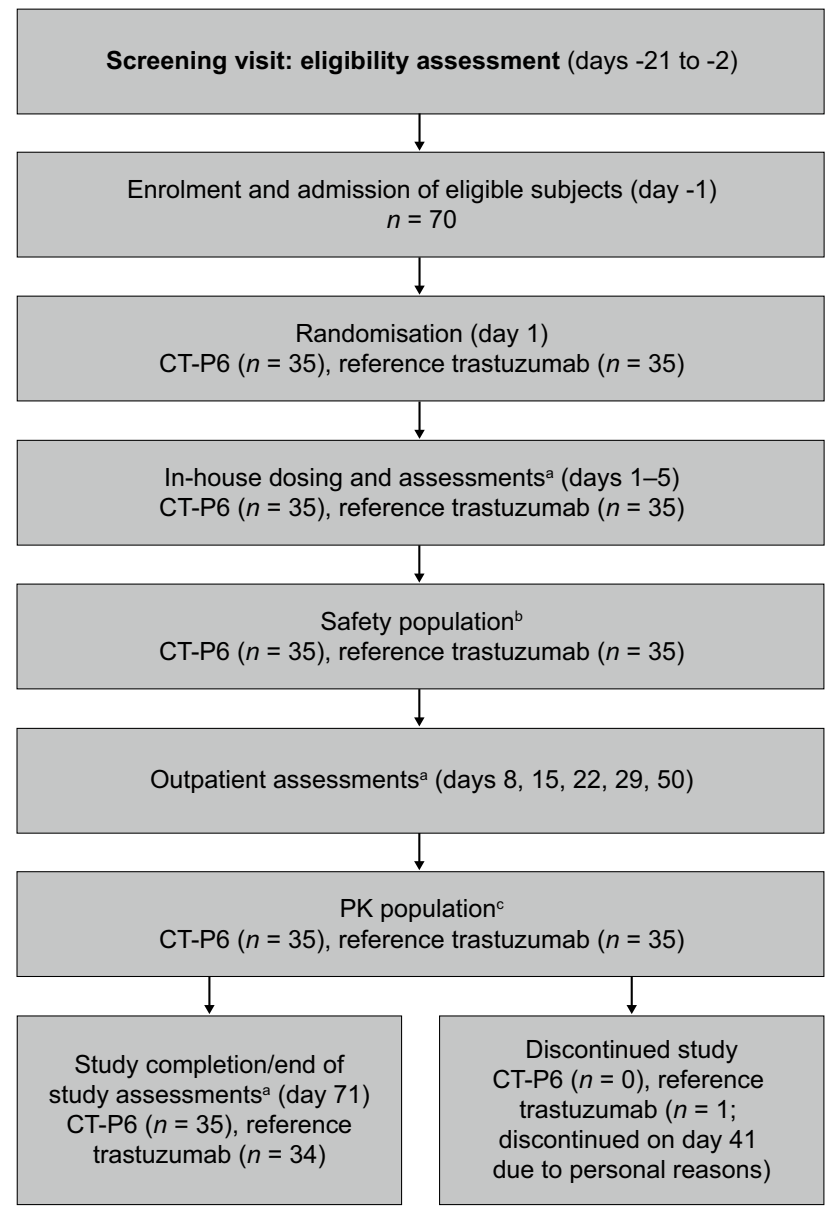

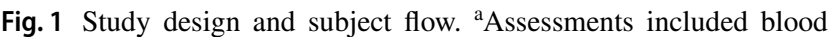
samples for PK analysis [days 1 (pre-dose then 1.5, 3, 6, $12 \mathrm{~h}$ after infusion start), 2 (24 h after infusion start), 3, 5, 8, 15, 22, 29, 50 and 71]; physical examination (days 3 and 71); clinical laboratory tests (days 2, 3, 5, 8, 15, 22, 29, 50 and 71); measurement of vital signs (days 1, 2, 3, 5, 8, 15, 22, 29, 50 and 71); electrocardiogram (days $1,3,5,15,29$ and 71); cardiac function (day 71); and levels of antidrug antibody and neutralising antibody [days 1 (pre-dose), 50 and 71]. Adverse event monitoring was conducted for the duration of the study. ${ }^{\text {b}}$ Safety population: all randomised subjects who received a complete or partial dose of either CT-P6 or reference trastuzumab. ${ }^{c} \mathrm{PK}$ population: all subjects who received a complete dose of either CT-P6 or reference trastuzumab and from whom at least one posttreatment PK sample with a concentration above the lower limit of quantification for trastuzumab was collected. $P K$ pharmacokinetic

or alcohol abuse. (For a full list of inclusion and exclusion criteria see Online Resource Tables A1 and A2).

\section{Sample size, randomisation and blinding}

The study was powered to demonstrate PK equivalence of CT-P6 and reference trastuzumab in primary PK endpoints [area under the serum concentration-time curve from time 0 to infinity $\left(\mathrm{AUC}_{\text {inf }}\right)$, area under the serum concentration-time curve from time 0 to the last quantifiable concentration $\left(\mathrm{AUC}_{\text {last }}\right)$, and the observed maximum serum concentration $\left.\left(C_{\max }\right)\right]$. Thirty-one subjects were required in each treatment arm to provide at least $80 \%$ power for a $90 \%$ confidence interval (CI) for the ratio of $\mathrm{AUC}_{\text {inf }}, \mathrm{AUC}_{\text {last }}$, and $C_{\max }$ within the equivalence margin of $80-125 \%$ [assuming a coefficient of variation of $30 \%$ and a ratio of geometric least squares (LS) means of 1]. Assuming a 10\% dropout rate, a sample size of approximately 70 subjects $(n=35$ per treatment arm) was required.

After an initial screening visit (conducted between day -21 and day -2 ), subjects were admitted to the study centre to undergo baseline assessments and confirm eligibility (day -1$)$. Eligible subjects were then randomised (day 1) in a 1:1 ratio to receive either CT-P6 or reference trastuzumab (Fig. 1). Randomisation codes were provided by PPD before the study began and were created using the PROC PLAN procedure in SAS ${ }^{\circledR}$ version 9.2 (SAS Institute Inc., Cary, NC, USA). Two sets of sealed code-break envelopes were supplied: one was retained at the study centre and one at the PPD Pharmacovigilance Reporting Department. The randomisation code was only broken after all final clinical data were recorded and all subjects were assigned to analysis sets. This randomisation included stratification by race (Japanese and non-Japanese). Dosing was conducted in a double-blinded fashion. All dosing solutions were prepared in identical infusion bags by a separate, designated, unblinded pharmacist and supplied to the treating clinician in a blinded manner.

\section{Experimental procedures}

Subjects received a single dose of either CT-P6 (6 mg/ $\mathrm{kg}$, Lot Number 13A3C003; CELLTRION Inc., Incheon, Republic of Korea) or US-licensed reference trastuzumab (Herceptin ${ }^{\circledR} ; 6$ mg/kg, Lot Number 3014296; Genentech Inc., South San Francisco, CA, USA), by intravenous infusion for $90 \mathrm{~min}( \pm 5 \mathrm{~min})$ on day 1 . Oral paracetamol (650 mg) was administered 30-60 min prior to infusion to reduce the risk of infusion-related reactions (IRRs). Subjects remained in the study centre until $96 \mathrm{~h}$ post-infusion. Further assessments of PK, safety and immunogenicity parameters were conducted up to 10 weeks post-dose, on an outpatient basis, with a final visit for end-of-study assessments on day 71 (Fig. 1).

\section{Study endpoints}

\section{Primary endpoints}

Blood samples for PK analysis were taken on days 1 (predose then 1.5, 3, 6 and $12 \mathrm{~h}$ after infusion start), 2 ( $24 \mathrm{~h}$ after infusion start), 3, 5, 8, 15, 22, 29, 50 and 71. Noncompartmental trastuzumab serum PK parameters were 
obtained for each treatment group. Primary PK endpoints were $\mathrm{AUC}_{\text {inf }}, \mathrm{AUC}_{\text {last }}$, and $C_{\text {max }}$. The pre-determined criterion used to establish PK equivalence of CT-P6 and reference trastuzumab (with respect to $\mathrm{AUC}_{\text {inf }}, \mathrm{AUC}_{\text {last }}$ and $C_{\max }$ ) was a $90 \% \mathrm{CI}$ for the ratio of geometric LS means of between 80 and $125 \%$.

\section{Secondary PK endpoints}

Secondary PK endpoints included the percentage of the area extrapolated for calculation of $\mathrm{AUC}_{\mathrm{inf}}\left(\% \mathrm{AUC}_{\mathrm{ext}}\right)$, time to $C_{\max }\left(T_{\max }\right)$, volume of distribution during the terminal phase $\left(V_{\mathrm{z}}\right)$, terminal elimination rate constant $\left(\lambda_{\mathrm{z}}\right)$, terminal elimination half-life $\left(t_{1 / 2}\right)$, and total body clearance (CL).

\section{Additional secondary endpoints: safety and immunogenicity}

Safety endpoints included assessment of adverse events (AEs), IRRs, clinical laboratory test results, vital signs, electrocardiogram (ECG), New York Heart Association classification, LVEF and physical examination. Immunogenicity was evaluated via measurement of anti-drug antibody (ADA) and neutralising antibody (NAb) levels (Fig. 1).

\section{Data analysis}

Statistical analyses were conducted using SAS ${ }^{\circledR}$ version 9.2. PK data were analysed using Phoenix ${ }^{\circledR}$ WinNonlin ${ }^{\circledR}$ Version 6.2.1 (Pharsight Corporation, St Louis, MO, USA). During analysis, PK samples taken before administration of CT-P6 or reference trastuzumab in which serum trastuzumab concentrations were below the lower limit of quantification (LLOQ) were listed as zero. For those taken after administration of CT-P6 or reference trastuzumab, the first value below the LLOQ was listed as LLOQ. Any subsequent serum concentration values below the LLOQ were listed as 'missing'. Log-transformed primary PK endpoints $\left(\mathrm{AUC}_{\text {inf }}, \mathrm{AUC}_{\text {last }}\right.$, and $\left.C_{\text {max }}\right)$ were analysed using an analysis of covariance (ANCOVA) model, with treatment as a fixed effect and race (Japanese and non-Japanese) as a covariate. The difference in geometric LS means between treatment groups and the associated $90 \%$ CIs was determined. These values were then back-transformed to calculate the ratio of geometric LS means and associated 90\% CIs.

AEs were coded using the Medical Dictionary for Regulatory Activities, version 18.1 and intensity gradings were recorded based on Common Terminology Criteria for Adverse Events, (CTCAE, version 4.03).

\section{Analysis populations}

All subjects who received a complete dose of either CT-P6 or reference trastuzumab, and from whom at least one post-treatment PK sample with a concentration above the LLOQ for trastuzumab was collected, were included in the PK analysis population. The safety population comprised all randomised subjects who received a complete or partial dose of either CT-P6 or reference trastuzumab.

\section{Results}

\section{Subjects}

Seventy healthy male subjects (24 of Japanese ethnicity) were recruited into the study, which was conducted between 22 December 2015 and 29 April 2016. Each treatment arm consisted of 12 Japanese subjects and 23 non-Japanese subjects (Table 1). Sixty-nine of the 70 enrolled subjects completed the study; one subject in the reference trastuzumab group was discontinued (due to personal reasons). All 70 subjects met the criteria for inclusion in both the PK and safety populations (Fig. 1).

\section{PK}

Equivalence of CT-P6 and reference trastuzumab in healthy male subjects was demonstrated, with $90 \%$ CIs for the geometric LS mean ratios of $\mathrm{AUC}_{\text {inf }}, \mathrm{AUC}_{\text {last }}$, and $C_{\max }$ within the predefined range of $80-125 \%$ (Table 2). Similar results were obtained in the Japanese sub-population (Online Resource Table A3). The overall PK profile of trastuzumab was similar in both the CT-P6 and reference trastuzumab groups (Fig. 2) and secondary PK endpoints $\left(\% \mathrm{AUC}_{\mathrm{ext}}\right.$, $T_{\max }, t_{1 / 2}, \lambda_{\mathrm{z}}, V_{\mathrm{z}}$, and CL) were comparable between treatment groups (Table 3).

\section{Safety}

Overall safety profiles were similar for both CT-P6 and reference trastuzumab, and both agents were well tolerated. In total, 37 treatment-emergent adverse events (TEAEs) were reported: ten subjects (28.6\%) reported TEAEs in the CT-P6 group, compared with 11 subjects $(31.4 \%)$ in the reference trastuzumab group. Headache was the most common TEAE, reported by two subjects $(5.7 \%)$ in the CT-P6 group and three subjects $(8.6 \%)$ in the reference trastuzumab group. A total of ten subjects $(14.3 \%)$ reported a TEAE considered related to study drug (five subjects in each treatment group) (Table 4).

With the exception of one subject in the reference trastuzumab group who experienced Grade 2 nausea and 
Table 1 Subject demographics (safety population)

\begin{tabular}{|c|c|c|c|}
\hline Characteristic & Overall $(n=70)$ & CT-P6 group $(n=35)$ & $\begin{array}{l}\text { Reference tras- } \\
\text { tuzumab group } \\
(n=35)\end{array}$ \\
\hline \multicolumn{4}{|l|}{ Age (years) } \\
\hline Median & 34.5 & 37.0 & 32.0 \\
\hline Range & $18-55$ & $20-55$ & $18-54$ \\
\hline \multicolumn{4}{|l|}{ Sex, $n(\%)$} \\
\hline Male & $70(100.0)$ & $35(100.0)$ & $35(100.0)$ \\
\hline \multicolumn{4}{|l|}{ Height $(\mathrm{cm})$} \\
\hline Mean (SD) & $175.2(7.8)$ & $175.7(8.2)$ & $174.8(7.4)$ \\
\hline Range & $159.6-192.6$ & $159.6-192.6$ & $160.3-191.8$ \\
\hline \multicolumn{4}{|l|}{ Weight (kg) } \\
\hline Mean (SD) & $77.3(9.9)$ & $77.8(8.6)$ & $76.8(11.2)$ \\
\hline Range & $59.2-101.8$ & $62.8-95.2$ & $59.2-101.8$ \\
\hline \multicolumn{4}{|c|}{ Body mass index $\left(\mathrm{kg} / \mathrm{m}^{2}\right)$} \\
\hline Mean (SD) & $25.2(2.8)$ & $25.3(2.7)$ & $25.1(3.0)$ \\
\hline Range & $19.4-29.8$ & $19.8-29.7$ & $19.4-29.8$ \\
\hline \multicolumn{4}{|l|}{ Ethnicity, $n(\%)$} \\
\hline Japanese & $24(34.3)$ & $12(34.3)$ & $12(34.3)$ \\
\hline White & $34(48.6)$ & $19(54.3)$ & 15 (42.9) \\
\hline $\begin{array}{l}\text { Black or African } \\
\text { American }\end{array}$ & $12(17.1)$ & $4(11.4)$ & $8(22.9)$ \\
\hline
\end{tabular}

Table 2 Primary PK data (PK population)

\begin{tabular}{lccll}
\hline PK parameter (unit) & \multicolumn{2}{l}{ Geometric LS means $^{\mathrm{a}}$} & $\begin{array}{l}\text { \% Ratio }{ }^{\mathrm{a}}(\mathrm{CT}-\mathrm{P} 6 / \mathrm{refer}- \\
\text { ence trastuzumab })\end{array}$ & 90\% CI \\
\cline { 2 - 5 } & CT-P6 $(n=35)$ & $\begin{array}{l}\text { Reference trastu- } \\
\text { zumab }(n=35)\end{array}$ & \\
\hline $\mathrm{AUC}_{\text {inf }}\left(\mathrm{h} \mu \mathrm{g} \mathrm{ml}^{-1}\right)$ & 19523.05 & 19709.36 & 99.05 & $93.00,105.51$ \\
$\mathrm{AUC}_{\text {last }}\left(\mathrm{h} \mu \mathrm{g} \mathrm{ml}^{-1}\right)$ & 18183.73 & 18312.53 & 99.30 & $92.85,106.20$ \\
$C_{\text {max }}\left(\mu \mathrm{g} \mathrm{ml}^{-1}\right)$ & 127.95 & 132.48 & 96.58 & $90.93,102.59$
\end{tabular}

An analysis of covariance was performed with the natural log-transformed PK data as the dependent variable, treatment as a fixed effect, and race as a covariate

$A U C_{i n f}$ area under the serum concentration-time curve from time 0 to infinity, $A U C_{\text {last }}$ area under the serum concentration-time curve from time 0 to the last quantifiable concentration, $C I$ confidence interval, $C_{\max }$ observed maximum measured serum concentration, $L S$ least squares, $P K$ pharmacokinetic

${ }^{a}$ The adjusted mean differences and $90 \%$ CIs for the differences were exponentiated to provide estimates of the ratio of adjusted geometric LS means (CT-P6/reference trastuzumab) and corresponding $90 \%$ CI values vomiting, all TEAEs were Grade 1 in severity. All TEAEs resolved by the end of the study, with the exception of one instance in a subject in the reference trastuzumab group (Gilbert's syndrome). No deaths, serious AEs, TEAEs of Grade 3 or higher, TEAEs due to cardiotoxicity, or TEAEs leading to study discontinuation occurred. Seven TEAEs relating to IRRs, hypersensitivity or anaphylactic reactions were reported (nausea, vomiting, chills, feeling of body temperature change, myalgia, dizziness, and headache). These seven TEAEs occurred in three subjects $(4.3 \%)$, one in the CT-P6 group and two in the reference trastuzumab group. No treatment-related effects on clinical laboratory results, vital sign measurements, ECG results, or physical examination findings occurred in any subject. No notable changes in LVEF were observed on day 71 in either group. Finally, no signs or symptoms of cardiac dysfunction occurred in any subject at the time points assessed.

\section{Immunogenicity}

None of the subjects had a positive ADA test result; therefore, the NAb analysis was not applicable. 

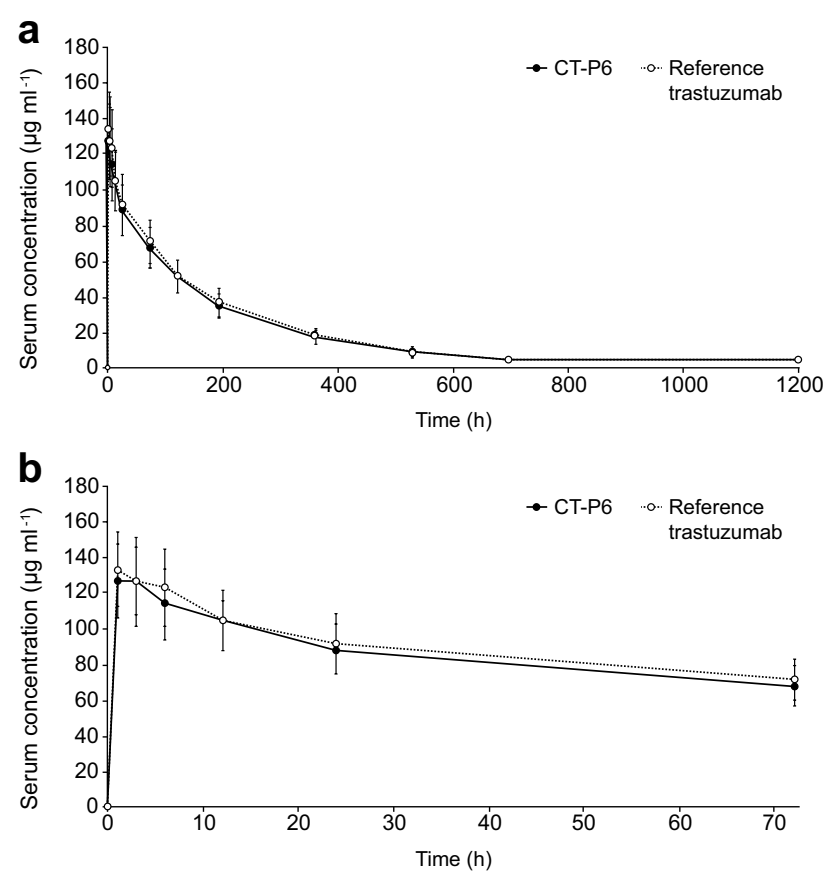

Fig. 2 Mean trastuzumab serum concentration-versus-time profiles a from 0 to $1200 \mathrm{~h}$ (50 days); b detailed view of $0-70 \mathrm{~h}$. Data are means \pm standard deviation. Data beyond day $50(1200 \mathrm{~h})$ are not shown, as these were below the lower limit of quantification for trastuzumab

Table 3 Secondary PK data (PK population)

\begin{tabular}{lll}
\hline PK parameter (unit) & CT-P6 $(n=35)$ & $\begin{array}{l}\text { Reference } \\
\text { trastuzumab } \\
(n=35)\end{array}$ \\
\hline $\mathrm{AUC}_{\text {ext }}(\%)$ & $6.81(1.17)$ & $7.00(2.52)$ \\
$t_{1 / 2}(h)$ & $189.31(36.03)$ & $183.68(37.53)$ \\
$T_{\max }$, median $(\mathrm{h})$ & 1.55 & 1.52 \\
$\lambda_{\mathrm{z}}\left(1 \mathrm{~h}^{-1}\right)$ & $0.0038(0.0007)$ & $0.0039(0.0007)$ \\
$V_{\mathrm{z}}(\mathrm{l})$ & $6.38(1.42)$ & $6.09(1.71)$ \\
$\mathrm{CL}\left(1 \mathrm{~h}^{-1}\right)$ & $0.0236(0.0043)$ & $0.0230(0.0048)$ \\
\hline
\end{tabular}

All data are means (standard deviation) unless otherwise specified

$\lambda_{z}$ terminal elimination rate constant, $A U C_{e x t}$ area extrapolated for calculation of area under the serum concentration-time curve from time 0 to infinity, $C L$ total body clearance, $P K$ pharmacokinetic, $t_{1 / 2}$ terminal elimination half-life, $T_{\max }$ time to observed maximum measured serum concentration, $V_{z}$ volume of distribution during the terminal phase

\section{Discussion}

These data demonstrate that CT-P6 and reference trastuzumab were equivalent in healthy subjects, as measured by the primary PK endpoints $\mathrm{AUC}_{\mathrm{inf}}, \mathrm{AUC}_{\text {last }}$, and $C_{\max }$. Similar results were seen in the Japanese sub-population.
Secondary PK endpoints $\left(\% \mathrm{AUC}_{\mathrm{ext}}, T_{\max }, t_{1 / 2}, \lambda_{\mathrm{z}}, V_{\mathrm{z}}\right.$, and $\mathrm{CL})$ were also comparable for CT-P6 and reference trastuzumab. Both agents were well tolerated, with the safety profile of CT-P6 comparable to that of reference trastuzumab. Immunogenicity did not differ between treatment groups (none of the trial subjects exhibited a positive ADA test result).

The FDA and EMA require that biosimilarity is demonstrated via a 'stepwise approach' that includes analytical, non-clinical and clinical data, with clinical evidence encompassing PK, efficacy, safety and immunogenicity. The importance of conducting a direct, comparative PK study between a biosimilar and the relevant reference product is highlighted by both regulatory agencies $[27,29]$. Thus, these data represent an important component of the regulatory information required for approval of CT-P6 in Europe and the USA. In common with most PK studies, this trial was conducted in healthy, male volunteers. Healthy subjects were used in this study to avoid the potentially high variability of trastuzumab exposure that may occur in patients with breast or gastric cancer. Male subjects were recruited for ethical reasons; as most patients who receive trastuzumab are female, females should be preferentially protected from the possibility of developing antibodies to trastuzumab, which may preclude or reduce the effectiveness of future trastuzumab therapy.

Trastuzumab is an established treatment option for patients with HER 2 + breast cancer $[9,14,15,17]$ and HER 2 + gastric and gastroesophageal junction cancer [19-21]. In clinical trials, trastuzumab is associated with increased pathological complete response rates and eventfree survival rates when used as part of a neoadjuvant treatment regimen in early HER 2 + breast cancer [31-33], and increased rates of disease-free and overall survival rates when used as a component of adjuvant treatment $[10,34,35]$. Addition of trastuzumab to chemotherapy in HER2 + MBC improves survival rates as well as increasing time to disease progression, time to treatment failure and duration of response [36-38]. Efficacy in HER2 + MBC is also seen when trastuzumab is used as a monotherapy [39]. Despite these clinical findings, oncologists report that patient access to trastuzumab is sometimes restricted due to cost [26]. Assuming equivalent efficacy, biosimilars are more cost-effective than the corresponding reference product, and their availability may, therefore, improve the financial sustainability of cancer treatment $[23,25]$ and improve patient access [26]. A recent study in Europe found that, on average, biosimilars were $15 \%$ less expensive than their corresponding reference product [40]. A Croatian budget impact analysis (BIA) that modelled the impact of the introduction of biosimilar trastuzumab predicted savings of up to $€ 0.69$ million in the initial year of introduction into that country (assuming a 35\% price discount), with up to 47 extra patients able to access trastuzumab [41]. Data from 
Table 4 TEAEs (safety

population)

\begin{tabular}{lll}
\hline & CT-P6 $(n=35)$ & $\begin{array}{l}\text { Reference } \\
\text { trastuzumab } \\
(n=35)\end{array}$ \\
\hline $\begin{array}{l}\text { Subjects with at least one TEAE, } n(\%) \\
\text { Most common TEAEs }{ }^{\mathrm{a}}, n(\%)\end{array}$ & $10(28.6)$ & $11(31.4)$ \\
Headache & $2(5.7)$ & $3(8.6)$ \\
Nasal congestion & $0(0)$ & $2(5.7)$ \\
Nausea & $0(0)$ & $2(5.7)$ \\
Any TEAE related to study drug & $5(14.3)$ & $5(14.3)$ \\
Most common TEAEs related to study drug ${ }^{\mathrm{a}}, n(\%)$ & & $3(8.6)$ \\
Headache & $2(5.7)$ & $2(5.7)$ \\
Nausea & $0(0)$ & \\
\hline
\end{tabular}

Data presented are $n(\%)$

$T E A E$ treatment-emergent adverse event

${ }^{\text {a }}$ TEAEs reported in more than one subject overall first-generation biosimilars prescribed in supportive cancer care [e.g. biosimilars of erythropoietins, erythropoiesisstimulating agent (ESA), or granulocyte-colony-stimulating factor (G-CSF) reference products] also demonstrate potential cost savings. For example, a BIA model of biosimilar ESA usage in Germany, France, Italy, Spain and the UK calculated a saving of up to $€ 146$ million, if all patients converted to biosimilar ESA, potentially freeing up budget for reallocation to anti-cancer treatments [42]. Another analysis conducted in the same countries assessing the use of biosimilar filgrastim estimated savings of $€ 32.70$ (1-day regimen) to $€ 457.84$ (14-day regimen), per treatment [43]. Use of erythropoietins and G-CSF increased following the introduction of biosimilar versions, in particular in countries in which access to biological products is restricted. In the UK, patient access to filgrastim increased substantially due to the introduction of a biosimilar version, the cost-effectiveness of which led to changes in clinical guidelines [44].

A number of trastuzumab biosimilars are currently at various stages of development. However, the types and amounts of non-clinical and clinical data available for each agent vary considerably [28]. Several are currently in, or about to enter, late-stage clinical trials, including FTMB/ ABP 980, PF-05280014 and HD201 [28]. SB3 has recently been approved by the EMA [45] and MYL-1401O has been approved for use by the US FDA [46]. Others have not been developed or evaluated according to the stringent guidelines defined by regulatory authorities in the US, Europe and some other countries [27, 29] and, thus, may be more correctly termed 'biomimics' or 'biocopies' rather than biosimilars [47].

A Phase III trial of CT-P6 is ongoing, in which the efficacy and safety of CT-P6 for neoadjuvant and adjuvant treatment are being compared with those of reference trastuzumab in HER2 + EBC (NCT02162667). Results from the neoadjuvant period show that the efficacy of CT-P6 was equivalent to that of reference trastuzumab, and safety profiles were also similar [48]. The results of the present study, therefore, add to the totality of evidence regarding CT-P6 required by US and European regulatory authorities, in addition to addressing the specific US requirement of similarity to an FDA-licensed product with respect to clinical PK [29] and the EMA requirement for a comparative clinical PK study [27].

Acknowledgements The authors thank all those involved in this study, including the subjects and investigators who participated. The study was sponsored by CELLTRION, Inc. (Incheon, Republic of Korea.) Medical writing support (in the form of development of a draft outline in consultation with the authors, development of first and subsequent drafts in consultation with the authors, assembling tables and figures, collating author comments, copyediting, fact checking and referencing) was provided by Hannah Mace, MPharmacol. at Aspire Scientific Limited [Bollington, UK; funded by CELLTRION Healthcare Co., Ltd (Incheon, Republic of Korea)].

\section{Compliance with ethical standards}

Conflict of interest The study was sponsored by CELLTRION, Inc. (Incheon, Republic of Korea). Medical writing support was funded by CELLTRION Healthcare Co., Ltd (Incheon, Republic of Korea). FJE serves as a consultant for Celltrion. JS is supported by the NIHR and the Imperial College, London, BRC. RW-H and PPD received payment from CELLTRION, Inc. for conducting the study. PW declares that he has no conflict of interest. SYL and SJL are employees of CELLTRION, Inc. SJL holds stock options in CELLTRION, Inc.

Research involving human participants and/or animals All procedures performed in studies involving human participants were in accordance with the ethical standards of the institutional and/or national research committee and with the 1964 Helsinki declaration and its later amendments or comparable ethical standards. 
Informed consent Informed consent was obtained from all individual participants included in the study.

Open Access This article is distributed under the terms of the Creative Commons Attribution 4.0 International License (http://creativecommons.org/licenses/by/4.0/), which permits unrestricted use, distribution, and reproduction in any medium, provided you give appropriate credit to the original author(s) and the source, provide a link to the Creative Commons license, and indicate if changes were made.

\section{References}

1. Carter P, Presta L, Gorman CM, Ridgway J, Henner D, Wong W, Rowland AM, Kotts C, Carver ME, Shepard HM (1992) Humanization of an anti-p185HER2 antibody for human cancer therapy. Proc Natl Acad Sci USA 89(10):4285-4289

2. Yarden Y, Sliwkowski MX (2001) Untangling the erbB signalling network. Nat Rev Mol Cell Biol 2(2):127-137. https://doi. org/10.1038/35052073

3. Slamon DJ, Godolphin W, Jones LA, Holt JA, Wong SG, Keith DE, Levin WJ, Stuart SG, Udove J, Ullrich A (1989) Studies of the HER-2/neu proto-oncogene in human breast and ovarian cancer. Science 244(4905):707-712

4. Gravalos C, Jimeno A (2008) HER2 in gastric cancer: a new prognostic factor and a novel therapeutic target. Ann Oncol 19(9):1523-1529. https://doi.org/10.1093/annonc/mdn169

5. Esteva FJ, Guo H, Zhang S, Santa-Maria C, Stone S, Lanchbury JS, Sahin AA, Hortobagyi GN, Yu D (2010) PTEN, PIK3CA, p-AKT, and p-p70S6K status: association with trastuzumab response and survival in patients with HER2-positive metastatic breast cancer. Am J Pathol 177(4):1647-1656. https://doi. org/10.2353/ajpath.2010.090885

6. Jorgensen JT, Hersom M (2012) HER2 as a prognostic marker in gastric cancer-a systematic analysis of data from the literature. J Cancer 3:137-144. https://doi.org/10.7150/jca.4090

7. Genentech (2017) Herceptin ${ }^{\circledR}$ (trastuzumab). Highlights of prescribing information. https:/www.accessdata.fda.gov/drugsatfda_docs/label/2017/103792s5337lbl.pdf. Accessed 9 Aug 2017

8. European Medicines Agency (2017) Herceptin ${ }^{\circledR}$ (trastuzumab). Summary of product characteristics. http://www.ema.europa.eu/ docs/en_GB/document_library/EPAR_-_Product_Information/ human/000278/WC500074922.pdf. Accessed 9 Aug 2017

9. Senkus E, Kyriakides S, Ohno S, Penault-Llorca F, Poortmans P, Rutgers E, Zackrisson S, Cardoso F, Committee EG (2015) Primary breast cancer: ESMO clinical practice guidelines for diagnosis, treatment and follow-up. Ann Oncol 26 Suppl 5:v8-v30. https://doi.org/10.1093/annonc/mdv298

10. Slamon D, Eiermann W, Robert N, Pienkowski T, Martin M, Press M, Mackey J, Glaspy J, Chan A, Pawlicki M, Pinter T, Valero V, Liu MC, Sauter G, von Minckwitz G, Visco F, Bee V, Buyse M, Bendahmane B, Tabah-Fisch I, Lindsay MA, Riva A, Crown J (2011) Adjuvant trastuzumab in HER2-positive breast cancer. N Engl J Med 365(14):1273-1283. https://doi.org/10.1056/ NEJMoa0910383

11. Gianni L, Dafni U, Gelber RD, Azambuja E, Muehlbauer S, Goldhirsch A, Untch M, Smith I, Baselga J, Jackisch C, Cameron D, Mano M, Pedrini JL, Veronesi A, Mendiola C, Pluzanska A, Semiglazov V, Vrdoljak E, Eckart MJ, Shen Z, Skiadopoulos G, Procter M, Pritchard KI, Piccart-Gebhart MJ, Bell R (2011) Treatment with trastuzumab for 1 year after adjuvant chemotherapy in patients with HER2-positive early breast cancer: a 4-year followup of a randomised controlled trial. Lancet Oncol 12(3):236-244. https://doi.org/10.1016/s1470-2045(11)70033-x
12. Esteva FJ, Valero V, Booser D, Guerra LT, Murray JL, Pusztai L, Cristofanilli M, Arun B, Esmaeli B, Fritsche HA, Sneige N, Smith TL, Hortobagyi GN (2002) Phase II study of weekly docetaxel and trastuzumab for patients with HER-2-overexpressing metastatic breast cancer. J Clin Oncol 20(7):1800-1808. https:// doi.org/10.1200/jco.2002.07.058

13. Fornier M, Esteva FJ, Seidman AD (2000) Trastuzumab in combination with chemotherapy for the treatment of metastatic breast cancer. Semin Oncol 27(6 Suppl 11):38-45 (discussion 92-100)

14. Cardoso F, Costa A, Senkus E, Aapro M, Andre F, Barrios CH, Bergh J, Bhattacharyya G, Biganzoli L, Cardoso MJ, Carey L, Corneliussen-James D, Curigliano G, Dieras V, El Saghir N, Eniu A, Fallowfield L, Fenech D, Francis P, Gelmon K, Gennari A, Harbeck N, Hudis C, Kaufman B, Krop I, Mayer M, Meijer H, Mertz S, Ohno S, Pagani O, Papadopoulos E, Peccatori F, Pernault-Llorca F, Piccart MJ, Pierga JY, Rugo H, Shockney L, Sledge G, Swain S, Thomssen C, Tutt A, Vorobiof D, Xu B, Norton L, Winer E (2017) 3rd ESO-ESMO international consensus guidelines for advanced breast cancer (ABC 3). Breast 28(1):16-33. https://doi.org/10.1016/j.breast.2016.10.001

15. Denduluri N, Somerfield MR, Eisen A, Holloway JN, Hurria A, King TA, Lyman GH, Partridge AH, Telli ML, Trudeau ME (2016) Selection of optimal adjuvant chemotherapy regimens for human epidermal growth factor receptor 2 (HER2)-negative and adjuvant targeted therapy for HER2-positive breast cancers: an American Society of Clinical Oncology guideline adaptation of the Cancer Care Ontario clinical practice guideline. J Clin Oncol 34(20):2416-2427. https://doi.org/10.1200/JCO.2016.67.0182

16. Giordano SH, Temin S, Kirshner JJ, Chandarlapaty S, Crews JR, Davidson NE, Esteva FJ, Gonzalez-Angulo AM, Krop I, Levinson J (2014) Systemic therapy for patients with advanced human epidermal growth factor receptor 2-positive breast cancer: American Society of Clinical Oncology clinical practice guideline. J Clin Oncol 32(19):2078-2099. https://doi.org/10.1200/ JCO.2013.54.0948

17. NCCN Guideline Panel (2017) National Comprehensive Cancer Network Clinical Practice Guidelines in Oncology. Breast cancer. Version 2.2017. https://www.nccn.org/professionals/physician_gls/pdf/breast.pdf. Accessed 9 Aug 2017

18. Bang YJ, Van Cutsem E, Feyereislova A, Chung HC, Shen L, Sawaki A, Lordick F, Ohtsu A, Omuro Y, Satoh T, Aprile G, Kulikov E, Hill J, Lehle M, Ruschoff J, Kang YK, ToGA Trial Investigators (2010) Trastuzumab in combination with chemotherapy versus chemotherapy alone for treatment of HER2-positive advanced gastric or gastro-oesophageal junction cancer (ToGA): a phase 3, open-label, randomised controlled trial. Lancet 376 (9742):687-697. https://doi.org/10.1016/S0140-6736(10)61121-X

19. Bartley AN, Washington MK, Colasacco C, Ventura CB, Ismaila N, Benson AB III, Carrato A, Gulley ML, Jain D, Kakar S (2016) HER2 testing and clinical decision making in gastroesophageal adenocarcinoma: guideline from the College of American Pathologists, American Society for Clinical Pathology, and the American Society of Clinical Oncology. J Clin Oncol 35(4):446-464

20. NCCN Guideline Panel (2017) National Comprehensive Cancer Network Clinical Practice Guidelines in Oncology. Gastric cancer. Version 2.2017. https://www.nccn.org/professionals/physician_gls/PDF/gastric.pdf. Accessed 9 Aug 2017

21. Smyth E, Verheij M, Allum W, Cunningham D, Cervantes A, Arnold D (2016) Gastric cancer: ESMO clinical practice guidelines for diagnosis, treatment and follow-up. Ann Oncol 27(suppl 5):v38-v49. https://doi.org/10.1093/annonc/mdw350

22. Fleck LM (2006) The costs of caring: who pays? Who profits? Who panders? Hastings Cent Rep 36(3):13-17

23. Cornes P (2012) The economic pressures for biosimilar drug use in cancer medicine. Target Oncol 7(1):57-67. https://doi. org/10.1007/s11523-011-0196-3 
24. Parkin DM (2001) Global cancer statistics in the year 2000. Lancet Oncol 2(9):533-543. https://doi.org/10.1016/ S1470-2045(01)00486-7

25. Tabernero J, Vyas M, Giuliani R, Arnold D, Cardoso F, Casali PG, Cervantes A, Eggermont AM, Eniu A, Jassem J (2017) Biosimilars: a position paper of the European Society for Medical Oncology, with particular reference to oncology prescribers. ESMO Open 1(6):e000142. https://doi.org/10.1136/ esmoopen-2016-000142

26. Lammers P, Criscitiello C, Curigliano G, Jacobs I (2014) Barriers to the use of trastuzumab for HER2 + breast cancer and the potential impact of biosimilars: a physician survey in the United States and emerging markets. Pharmaceuticals (Basel) 7(9):943-953. https://doi.org/10.3390/ph7090943

27. European Medicines Agency (2014) Guideline on similar biological medicinal products containing biotechnology-derived proteins as active substance: non-clinical and clinical issues. http://www. ema.europa.eu/docs/en_GB/document_library/Scientific_guideline/2015/01/WC500180219.pdf. Accessed 9 Aug 2017

28. Generics and Biosimilars Initiative (2017) Biosimilars of trastuzumab. http://www.gabionline.net/Biosimilars/General/Biosimilars-of-trastuzumab. Accessed 9 Aug 2017

29. US Food and Drug Administration (2015) Scientific considerations in demonstrating biosimilarity to a reference product. Guidance for industry. http://www.fda.gov/downloads/Drugs/GuidanceComplianceRegulatoryInformation/Guidances/UCM291128. pdf. Accessed 9 Aug 2017

30. Lemery SJ, Ricci MS, Keegan P, McKee AE, Pazdur R (2017) FDA's approach to regulating biosimilars. Clin Cancer Res 23(8):1882-1885. https://doi.org/10.1158/1078-0432.ccr-16-1354

31. Gianni L, Eiermann W, Semiglazov V, Manikhas A, Lluch A, Tjulandin S, Zambetti M, Vazquez F, Byakhow M, Lichinitser M, Climent MA, Ciruelos E, Ojeda B, Mansutti M, Bozhok A, Baronio R, Feyereislova A, Barton C, Valagussa P, Baselga J (2010) Neoadjuvant chemotherapy with trastuzumab followed by adjuvant trastuzumab versus neoadjuvant chemotherapy alone, in patients with HER2-positive locally advanced breast cancer (the NOAH trial): a randomised controlled superiority trial with a parallel HER2-negative cohort. Lancet 375(9712):377-384. https:// doi.org/10.1016/s0140-6736(09)61964-4

32. Untch M, Rezai M, Loibl S, Fasching PA, Huober J, Tesch H, Bauerfeind I, Hilfrich J, Eidtmann H, Gerber B, Hanusch C, Kuhn T, du Bois A, Blohmer JU, Thomssen C, Dan Costa S, Jackisch C, Kaufmann M, Mehta K, von Minckwitz G (2010) Neoadjuvant treatment with trastuzumab in HER2-positive breast cancer: results from the GeparQuattro study. J Clin Oncol 28(12):2024 2031. https://doi.org/10.1200/jco.2009.23.8451

33. Untch M, Fasching PA, Konecny GE, Hasmuller S, Lebeau A, Kreienberg R, Camara O, Muller V, du Bois A, Kuhn T, Stickeler E, Harbeck N, Hoss C, Kahlert S, Beck T, Fett W, Mehta KM, von Minckwitz G, Loibl S (2011) Pathologic complete response after neoadjuvant chemotherapy plus trastuzumab predicts favorable survival in human epidermal growth factor receptor 2-overexpressing breast cancer: results from the TECHNO trial of the AGO and GBG study groups. J Clin Oncol 29(25):3351-3357. https://doi.org/10.1200/jco.2010.31.4930

34. Romond EH, Perez EA, Bryant J, Suman VJ, Geyer CE Jr, Davidson NE, Tan-Chiu E, Martino S, Paik S, Kaufman PA, Swain SM, Pisansky TM, Fehrenbacher L, Kutteh LA, Vogel VG, Visscher DW, Yothers G, Jenkins RB, Brown AM, Dakhil SR, Mamounas EP, Lingle WL, Klein PM, Ingle JN, Wolmark N (2005) Trastuzumab plus adjuvant chemotherapy for operable HER2-positive breast cancer. N Engl J Med 353(16):1673-1684. https://doi. org/10.1056/NEJMoa052122

35. Perez EA, Romond EH, Suman VJ, Jeong JH, Davidson NE, Geyer CE Jr, Martino S, Mamounas EP, Kaufman PA, Wolmark
N (2011) Four-year follow-up of trastuzumab plus adjuvant chemotherapy for operable human epidermal growth factor receptor 2-positive breast cancer: joint analysis of data from NCCTG N9831 and NSABP B-31. J Clin Oncol 29(25):3366-3373. https:// doi.org/10.1200/jco.2011.35.0868

36. Marty M, Cognetti F, Maraninchi D, Snyder R, Mauriac L, Tubiana-Hulin M, Chan S, Grimes D, Anton A, Lluch A, Kennedy J, O'Byrne K, Conte P, Green M, Ward C, Mayne K, Extra JM (2005) Randomized phase II trial of the efficacy and safety of trastuzumab combined with docetaxel in patients with human epidermal growth factor receptor 2-positive metastatic breast cancer administered as first-line treatment: the M77001 study group. J Clin Oncol 23(19):4265-4274. https://doi.org/10.1200/ jco.2005.04.173

37. Slamon DJ, Leyland-Jones B, Shak S, Fuchs H, Paton V, Bajamonde A, Fleming T, Eiermann W, Wolter J, Pegram M, Baselga J, Norton L (2001) Use of chemotherapy plus a monoclonal antibody against HER 2 for metastatic breast cancer that overexpresses HER2. N Engl J Med 344(11):783-792. https://doi.org/10.1056/ nejm200103153441101

38. Singh JC, Jhaveri K, Esteva FJ (2014) HER2-positive advanced breast cancer: optimizing patient outcomes and opportunities for drug development. Br J Cancer 111(10):1888-1898. https://doi. org/10.1038/bjc.2014.388

39. Vogel CL, Cobleigh MA, Tripathy D, Gutheil JC, Harris LN, Fehrenbacher L, Slamon DJ, Murphy M, Novotny WF, Burchmore M, Shak S, Stewart SJ, Press M (2002) Efficacy and safety of trastuzumab as a single agent in first-line treatment of HER2-overexpressing metastatic breast cancer. J Clin Oncol 20(3):719-726. https://doi.org/10.1200/jco.2002.20.3.719

40. Remuzat C, Dorey J, Cristeau O, Ionescu D, Radiere G, Toumi M (2017) Key drivers for market penetration of biosimilars in Europe. J Mark Access Health Policy 5(1):1272308. https://doi. org/10.1080/20016689.2016.1272308

41. Cesarec A, Likić R (2017) Budget impact analysis of biosimilar trastuzumab for the treatment of breast cancer in Croatia. Appl Health Econ Health Policy 15(2):277-286. https://doi. org/10.1007/s40258-016-0285-7

42. Abraham I, Han L, Sun D, MacDonald K, Aapro M (2014) Cost savings from anemia management with biosimilar epoetin alfa and increased access to targeted antineoplastic treatment: a simulation for the EU G5 countries. Future Oncol 10(9):1599-1609. https:// doi.org/10.2217/fon. 14.43

43. Aapro M, Cornes P, Abraham I (2012) Comparative costefficiency across the European G5 countries of various regimens of filgrastim, biosimilar filgrastim, and pegfilgrastim to reduce the incidence of chemotherapy-induced febrile neutropenia. J Oncol Pharm Pract 18(2):171-179. https://doi. org/10.1177/1078155211407367

44. IMS Institute for Healthcare Informatics (2016) Delivering on the potential of biosimilar medicines. The role of functioning competitive markets. http://www.medicinesforeurope.com/wpcontent/uploads/2016/03/IMS-Institute-Biosimilar-Report-March2016-FINAL.pdf. Accessed 9 Aug 2017

45. European Medicines Agency. Ontruzant. http://www.ema.europa. eu/docs/en_GB/document_library/Summary_of_opinion_-_Initial_authorisation/human/004323/WC500234791.pdf. Accessed 11 Jan 2018

46. US Food and Drug Administration. Ogivri prescribing information. https://www.accessdata.fda.gov/drugsatfda_docs/ label/2017/761074s000lbl.pdf. Accessed 11 Jan 2018

47. Dorner T, Kay J (2015) Biosimilars in rheumatology: current perspectives and lessons learnt. Nat Rev Rheumatol 11(12):713-724. https://doi.org/10.1038/nrrheum.2015.110

48. Stebbing J, Baranau Y, Baryash V, Manikhas A, Moiseyenko V, Dzagnidze G, Zhavrid E, Boliukh D, Stroyakovskii D, 
Pikiel J, Eniu A, Komov D, Morar-Bolba G, Li RK, Rusyn A, Lee SJ, Lee SY, Esteva FJ (2017) CT-P6 compared with reference trastuzumab for HER2-positive breast cancer: a randomised, double-blind, active-controlled, phase 3 equivalence trial. Lancet Oncol 18(7):917-928. https://doi.org/10.1016/ s1470-2045(17)30434-5 